\section{Error risk in the decision- making process}

\author{
Pier Luigi Baldi \\ Department of Psychology, University \\ of the Sacred Heart, Milan, Italy
}

\section{Abstract}

This research starts from the assumption, widely observed in literature, that stress and distraction involve risks of error, especially in high-density decision-making work situations, including Urgent Care-Emergency Departments. Three groups of undergraduates, 20 subjects each, were given fifteen multiplechoice logical questions: one group worked under stress; the second group worked under stress and was distracted twice; the third group worked under conditions that were neither stressful nor disturbing. The highest number of correct answers was generally scored by those working under quiet conditions. The group who worked under stress and was disturbed twice scored a greater number of correct answers than the group working under stress. For exploratory purposes, eight undergraduates were exposed to a condition of attentional disturbance for the entire duration of the test; they registered a significant lengthening of response times and a significant negative effect on their performance.

\section{Introduction}

The data of several psychological research studies, conducted since the 1960 s, have evidenced the incompleteness of an explanation of the decision-making process in exclusively rational terms. The usefulness of an integrated approach to decision making, i.e. an approach that takes into account the emotional dimension, was emphasised, among the first theorists and researchers, by Zajonc. ${ }^{1}$ In the course of his studies, Zajonc concluded that prompt, automatic reactions to stimuli are often affective in nature, and that they guide information processing. In his opinion, all perceptions have an affective component; it follows that we do not see a house, but $a$ fine house, an ugly house, a pretentious house. ${ }^{2}$ Slovic et al. ${ }^{3}$ pointed out that, until some years ago, the affective aspects of judgement and decision making were seldom identified.

In this frame, we must mention the dual process theories. ${ }^{4,5}$ These theories argue that in the process of selection operate two different modes: the cognitive-analytic and the intu- itive-emotional. Their respective contribution to decision making appears to vary according to circumstances, although the affective dimension is believed to play a leading role in thinking, cognition, and information processing. Noteworthy are also several researches which highlight the risks of decisions made in a disagreeable and stressful mood. ${ }^{6-8}$

The neurosciences too have forefronted the role of the affective dimension in decision making. Damasio, ${ }^{9,10}$ for example, determines somatic markers, i.e. automatic emotion-based mechanisms identifying the indicators of the levels of subjective acceptability of the different options at stake, as providing fundamental support to decision making.

The above mentioned studies are part of a key field of research to understand the difficult circumstances of several workers, among whom the health staff of the Urgent CareEmergency Departments (EDs), who are engaged in very demanding jobs. The stress conditions that can follow may involve risks of error ascribable, in particular, to anxiety, weariness, inattention.

Two words that often recur in describing emergency workers' difficulties are multitasking and overcrowding. The former term, borrowed from information technology, is applied to an operating system which allows to run more programs simultaneously; the same word, transferred to emergency-urgency, depicts the situation of workers having to take care of persons whose lives are in peril and, at the same time, of other patients who need diversified treatments. The latter word, overcrowding, often mentioned in literature on work environment in Urgent Care-EDs, starting from the United States, concerns the frequent disproportion between available health staff and the overwhelming number of patients with their requests for help. An interesting analysis of the work of Urgent Care-EDs is presented by Iscra and Zambon. ${ }^{11}$ They write: The emergency departments as well as the operating rooms and the intensive care units are at the high risk of accidents: the work is complex, frenetic and can seem chaotic to an external observer... Simultaneously taking care of several patients in a noisy and continuously evolving place, with frequent interruptions to admit a new patient or for the sudden worsening of the clinical conditions of a patient already hospitalized, can easily lead to error. Iscra and Zambon $^{11}$ report that $15-20 \%$ of medical malpractice in US hospitals is estimated to occur in EDs; they also document the results of an Australian research asserting that of all errors occurred in EDs, most could be ascribable to work organisation and could have been prevented.

In this research, which is a pilot study anticipating further experiments, we tried to assess the incidence of stress and distraction on deci-
Correspondence: Pier Luigi Baldi, Department of Psychology, University of the Sacred Heart, largo Gemelli 1, 20123 Milan, Italy.

Tel. +39.02.7234.2284 - Fax: +39.02 .7234 .2280 .

E-mail: pier.baldi@unicatt.it

Key words: decision-making, error risk, emergency department.

Received for publication: 18 November 2013.

Revision received: 14 January 2014.

Accepted for publication: 15 January 2014.

This work is licensed under a Creative Commons Attribution 3.0 License (by-nc 3.0).

(c) Copyright P.L. Baldi, 2014

Licensee PAGEPress, Italy

Emergency Care Journal 2014; 10:2119

doi:10.4081/ecj.2014.2119

sion making and, consequently, to estimate the risk of error in high-density decision-making contexts like hospitals' EDs. The study adopts the paradigm of a previous survey ${ }^{12}$ which evaluated the responses of two groups of university students to a number of multiple-choice logical questions under two different conditions. We used a task of logic because in a previous study $^{13}$ this task showed good discriminative capability and, above all, a medium-high level of difficulty, the latter being a requirement which we thought would provide a contribution to the study of complex work situations, such as those of Urgent Care-EDs. The performance of the subjects of the experimental group, on whom was induced a condition of stress by making them work individually, in the presence of the experimenter, and by asking them to answer the questions in the shortest time possible, was, as hypothesized, significantly poorer than the control group's, whose participants were simultaneously answering the questions in a university classroom with no time constraints. To assess whether the simultaneous occurrence of stress and distraction induces more difficulties in decision making and, therefore, further lowers performance, the experiment was designed to include three separate conditions, represented by three groups of university students respectively. Two groups worked under conditions similar to those of the previously outlined research; the participants of the third group, besides working under the same conditions of stress of the experimental group, were interrupted twice during their activity, each time for about 60 sec. 


\section{Materials and Methods}

\section{Participants}

Sixty university students aged between 19 and 25 were selected on the basis of a Raven's SPM score $>75^{\text {th }}$ percentile rank, and split into three groups of 20 subjects each, equally divided by gender.

One group worked under stress conditions; the second group worked under conditions of stress and attentional disturbance; the third group worked under conditions that were neither stressful nor disturbing. Experimental design and distribution of the subjects are outlined in Table 1.

\section{Materials and procedure}

The participants were administered fifteen multiple-choice alphanumeric series, and asked to add a new logically pertinent element to each series. The correct answer was to be sought among three alternatives by half of the subjects and among four alternatives by the other half (Table 2); the latter condition implies a greater decision-making load.

To answer the questions above, it is necessary to identify the ordering principle of each series. For example, in the case of the series 1A 3C 6F 10L (Table 2), it presents a sequence of letters determined by progressive increase of Italian alphabet between-letter positions (between $\mathrm{A}$ and $\mathrm{C}$ there is one position, namely $\mathrm{B}$; between $\mathrm{C}$ and $\mathrm{F}$, two positions, and so on); superscript numbers correspond to the positional value of the letters (the positional value of $A$ in the alphabetical sequence is 1 , the value of $\mathrm{C}$ is 3 , etc.). On these bases, the correct answer to the series is $15 \mathrm{Q}$, since there are four letters between $\mathrm{L}$ and $\mathrm{Q}$ (one letter more than between $\mathrm{F}$ and $\mathrm{L}$ ) and $\mathrm{Q}$ is the $15^{\text {th }}$ letter of the Italian A-to-Z alphabet.

The subjects of the group working under stress conditions and of the group working under conditions of stress and attentional disturbance performed the decision task individually, at the office of the experimenter. Each participant was given the opportunity to return to one or more logical series, in case of doubt or non-response. Each correct answer scored a point. For each participant were considered the number of correct answers and the time taken. From the time taken by the group exposed to the two distracting interruptions was subtracted the time during which participants were not able to work; for the two interruptions, a random between-subjects time order was followed. The logical series were presented in random between-subjects order. Tasks were anonymous.

\section{Statistical analysis}

The Pearson correlation coefficient $r$ between time taken and number of correct answers was measured.

Factorial variance analysis was also calculated for each of the dependent variables (response times and number of correct answers) by assuming in both cases treatment, gender and number of alternatives as independent variables.

The Scheffé post hoc test was used to evaluate significant differences among the groups under different treatments, both in response times and in number of correct answers.

\section{Results and Discussion}

The correlation coefficient between response times and number of correct answers is highly significant $(\mathrm{r}=0.62, \mathrm{P}<0.01)$, which proves that being allowed to work under neither stress nor distractions promotes performance quality.

The analysis of response time variance shows highly significant interaction between type of treatment and gender $\left(\mathrm{F}_{2,59}=6.25\right.$, $\mathrm{P}<0.01$ ), as well as very highly significant differences among treatments $\left(\mathrm{F}_{2,59}=81.52\right.$, $\mathrm{P}<0.001)$ and significant differences between response alternatives $\left(\mathrm{F}_{1,59}=4.68, \mathrm{P}<0.05\right)$.

The female gender has longer execution times under quiet conditions, displaying more motivation and ability of sustained attention, and seems to be less influenced by the distracting events, thus confirming, compared to the male gender, greater ability of sustained attention along with independence from stimuli external to the task (Figure 1). Moreover, Figure 1 shows faster response times in the group that answered under stress conditions,

Table 1. Composition of the sample.

\begin{tabular}{lccccc} 
Groups & \multicolumn{2}{c}{$\begin{array}{c}\text { Males } \\
\text { Alternative answers } \\
\text { Three }\end{array}$} & $\begin{array}{c}\text { Fomales } \\
\text { Alternative answers } \\
\text { Three }\end{array}$ & Tour \\
Stress conditions & 5 & 5 & 5 & 5 & 20 \\
Stress conditions and distraction & 5 & 5 & 5 & 5 & 20 \\
\hline Non-stress conditions & 5 & 5 & 5 & 5 & 20 \\
Total & 15 & 15 & 15 & 15 & 60 \\
\hline
\end{tabular}

Table 2. Examples of alphanumeric logical series with three and four alternative answers.

\begin{tabular}{|c|c|c|c|c|}
\hline Logical series & \multicolumn{4}{|c|}{ Three alternative answers ${ }^{\circ}$} \\
\hline $1 \mathrm{~A} \quad 3 \mathrm{C} \quad 6 \mathrm{~F} \quad 10 \mathrm{~L}$ & $14 \mathrm{P}$ & $15 Q$ & & $16 \mathrm{R}$ \\
\hline A26 B39 C412 & D515 & D58 & & D5125 \\
\hline \multirow[t]{2}{*}{$\mathrm{L}^{28} \mathrm{M}^{327} \mathrm{~L}^{464} \mathrm{M}^{5125}$} & $L^{6216}$ & $M^{6236}$ & & $0^{6216}$ \\
\hline & \multicolumn{4}{|c|}{ Four alternative answers } \\
\hline $\mathrm{B}^{2} \mathrm{D}^{4} \mathrm{H}^{8}$ & $\mathrm{~N}^{12}$ & $\mathrm{P}^{16}$ & $\mathrm{R}^{12}$ & $R^{16}$ \\
\hline $\begin{array}{llll}\mathrm{H}^{8} & \mathrm{G}^{7} & \mathrm{I} 9 & \mathrm{~F}^{6} \\
\end{array}$ & $5 \mathrm{~L}$ & $10 \mathrm{~F}$ & $L 10$ & $11 \mathrm{M}$ \\
\hline VUZ20 RQS16 NMO12 & BAD8 & GHI8 & HGI8 & HGI10 \\
\hline
\end{tabular}

${ }^{\circ}$ The correct answer is in italics.

Table 3. Second administration of the test: times and correct answers.

\begin{tabular}{lcccc} 
Order & Gender & Alternatives & Time $(\mathrm{s})$ & Correct answers \\
1 & M & 3 & 582 & 5 \\
2 & M & 3 & 601 & 4 \\
\hline 3 & M & 4 & 730 & 3 \\
4 & M & 4 & 746 & 4 \\
\hline 5 & F & 3 & 541 & 6 \\
6 & F & 3 & 518 & 5 \\
\hline 7 & F & 4 & 912 & 2 \\
8 & F & 4 & 894 & 3 \\
\hline Mean & - & - & 690.5 & 4 \\
\hline
\end{tabular}




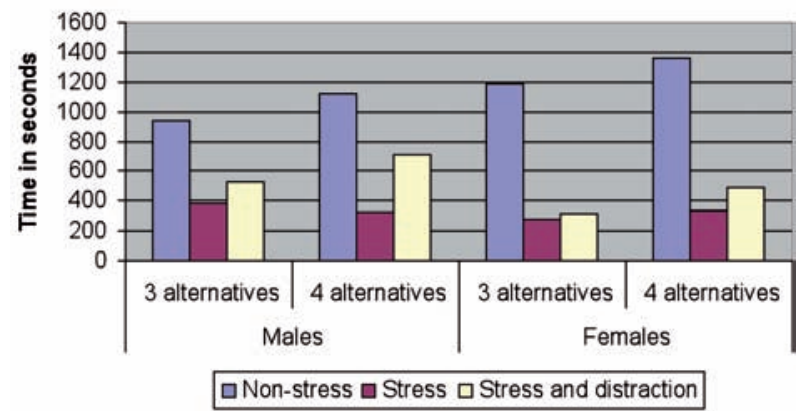

Figure 1. Mean response times among the groups of participants.

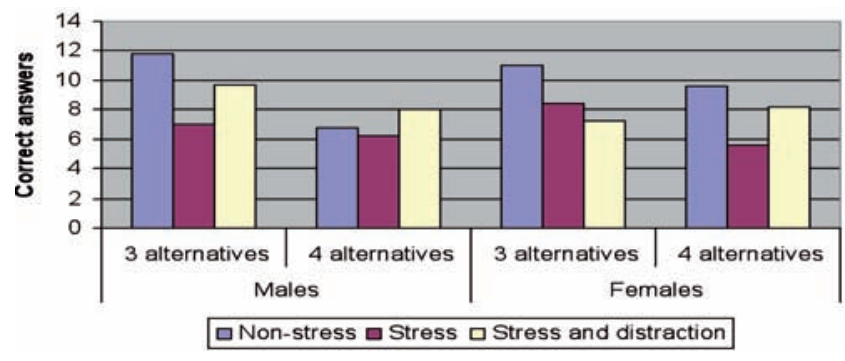

Figure 2. Mean of correct answers among the groups of participants. and it also attests, as hypothesized, that choosing among three alternative answers allowed faster performance than choosing among four alternatives.

The Scheffé post hoc test shows significant differences among the response times of the three groups who worked under different conditions; in most cases, these differences are very highly significant.

Variance analysis conducted on the number of correct answers does not show significant interactions. Highly significant differences are observed among the three conditions $\left(\mathrm{F}_{2,59}=6,51, \mathrm{P}<0.01\right)$ and between response alternatives $\left(\mathrm{F}_{1,59}=7.25, \mathrm{P}<0.01\right)$; as hypothesized, the highest number of correct answers was scored in three out of four cases by those who worked under quiet conditions, and in almost all cases by those having to choose the correct answer among three alternatives (Figure 2).

The Scheffé post hoc test shows that the group who worked under stress and distraction scored a greater number of correct answers than the group working under stress. This result prompts some considerations, as we shall shortly see.

\section{Conclusions}

The highest number of correct answers by the subgroup working under conditions of stress and distraction compared to those of the group working under stress conditions prompted a reconsideration of the procedure used to disrupt the attention functions of the participants. The procedure consisted of two distracting episodes, both announced with a sixty-second advance notice; notices were sometimes given on passing from one question to another, and they sometimes accelerated the provision of, most likely already found, answers. Thus, it is probable that the adopted procedure never had a particularly negative effect on the activity conducted. For exploratory purposes, eight students (4 males and 4 females) with a Raven's SPM score $>75^{\text {th }}$ percentile rank (thus, comparable to those of the outlined research) were subsequently selected; they were exposed to a condition of attentional disturbance for the entire duration of the test. This disturbance mode is probably more similar than the previous one to what can happen at hospitals, in Urgent Care-EDs. The eight students registered a significant lengthening of response times and a significant negative effect on their performance (Table 3). If we imagine the fifteen questions of the logical task of this study as so many modules in which it can be divided, we can advance a sufficiently plausible hypothesis on the different effect exerted by the two disturbance modes employed on attention functions. In the first case, the two distracting conditions could affect the moments of transition from one module to the next, or, at the most, cause difficulties in the solution of only two modules out of fifteen. In the second case, the eight participants were disturbed with different questions and considerations transversely through the modules, for the entire duration of the test; their discomfort and irritation were manifest.

The two different disturbance modes call to mind an amusing story told by Simon ${ }^{14,15}$ who showed that the solution of problems by human beings, who are agents with bounded rationality, necessarily proceeds through the decomposition of a complex problem; in this way, smaller subproblems are obtained that can be solved independently one from another. In Simon's story, ${ }^{14}$ the protagonists are two talented watchmakers: Tempus and Hora. Both of them were highly regarded, and the phones in their workshops rang frequently. However, Hora prospered, while Tempus became poorer and poorer and finally lost his shop. What was the reason? The watches the men made consisted of about 1000 parts each. Tempus had so constructed his watches that if he had one partly assembled and had to put it down - e.g. to answer the phone - it immediately fell to pieces and had to be reassembled from the ele- ments. The better the customers liked his watches, the more they phoned him, the more difficult it became for him to find enough uninterrupted time to finish a watch. The watches that Hora made were no less complex than those of Tempus. But he had designed them so that he could put together subassemblies of about ten elements each. Ten of these subassemblies, again, could be put together into a larger subassembly; and a system of ten of the latter subassemblies constituted the whole watch. Hence, when Hora had to put down a partly assembled watch in order to answer the phone, he lost only a small part of his work. The finished subassemblies did not fall apart. Thus, he assembled his watches in only a fraction of the time it took Tempus. Is not the first mode of attentional disturbance reminiscent of the conditions in which Hora worked? And, is not the second mode reminiscent of those of poor Tempus?

\section{References}

1. Zajonc RB. Attitudinal effects of mere exposure. J Pers Soc Psychol 1968;9:1-27.

2. Zajonc RB. Feeling and thinking: preferences need no inferences. Am Psychol 1980;35:151-75.

3. Slovic P, Finucane M, Peters E, MacGregor DG. The affect heuristic. In: Gilovich T, Griffin D, Kahneman D, eds. Heuristic and biases: the psychology of intuitive judgment. New York, NY: Cambridge University Press; 2002. pp 397-420.

4. Sloman SA. The empirical case for two systems of reasoning. Psychol Bull 1996;119:3-22.

5. Chaiken S, Trope Y. Dual-process theories in social psychology. New York, NY: Guilford Press; 1999.

6. Bower GH, Cohen PR. Emotional influences in memory and thinking: data and theory. In: Clark MS, Fiske ST, eds. Affect and cognition: the 17th annual Carnegie 
symposium on cognition. Hillsdale, NJ: Erlbaum; 1982. pp 291-331.

7. Garety PA, Hemsley DR, Wessely S. Reasoning in deluded schizophrenic and paranoid patients: Biases in performance on a probabilistic inference task. J Nerv Ment Dis 1991;179:194-201.

8. Bensi L, Giusberti F. Trait anxiety and reasoning under uncertainty. Pers Indiv Differ 2007;43:827-38.

9. Damasio AR. Descartes' error: emotion, reason, and the human brain. New York, NY: Avon; 1994.

10. Damasio AR. The somatic marker hypothesis and the possible functions of the pre- frontal cortex. Philos T Roy Soc B 1996;351:1413-20.

11. Iscra F, Zambon M. [Errore in medicina]. In: Gullo A, Murabito P, eds. [Governo clinico e medicina perioperatoria. Organizzazione, formazione, performance, eccellenza]. [Book in Italian]. Milano: Springer-Verlag Italia; 2012. pp 81100.

12. Baldi PL. Complex decision-making: initial results of an empirical study. Emerg Care J 2011;3:35-6.

13. Baldi PL, Amoretti G. [Livelli di formazione al termine della scuola media superiore e inserimento universitario: indagine comparativa su un campione di 1242 studenti di otto indirizzi di scuola secondaria di secondo grado]. In: Amoretti G, Baldi PL, Piazzini A, Schenkel M, Spairani M, eds. [Valorizzare i talenti. Test attitudinali, orientamento ed efficienza del sistema universitario]. [Book in Italian]. Milano: Franco Angeli; 1993. pp 135-67.

14. Simon HA. The architecture of complexity. In: Simon HA, ed. The sciences of the artificial. Cambridge, MA: MIT Press; 1969. pp 192-229.

15. Simon HA. Models of bounded rationality. Cambridge, MA: MIT Press; 1982. 